\title{
Closing the gaps in tobacco endgame evidence: a scoping review
}

\author{
Cheneal Puljević, 1,2,3 Kylie Morphett (D) ,1,2 Marita Hefler (D) 1,4 \\ Richard Edwards (1) , ${ }^{1,5}$ Natalie Walker, ${ }^{1,6,7}$ David P Thomas (1) , 1,4 \\ Md Arifuzzaman Khan, 1,2 Andrew Perusco, 1,8 Michael Le Grande, 1,9 \\ Katherine Cullerton, ${ }^{1,2}$ Driss Ait Ouakrim, ${ }^{1,10}$ Georgia Carstensen, ${ }^{1,2}$ David Sellars, ${ }^{1,2,11}$ \\ Janet Hoek (D) , 1,5 Ron Borland, 1,9,10 Billie Bonevski (D) ,'12 Tony Blakely, 1,10 \\ Claire Brolan, ${ }^{1,2}$ Coral E Gartner (1) 1,2
}

\begin{abstract}
- Additional supplemental material is published online only. To view, please visit the journal online (http://dx.doi. org/10.1136/tobaccocontrol2021-056579).
\end{abstract}

For numbered affiliations see end of article.

\section{Correspondence to} Associate Professor Coral E Gartner, NHMRC Centre of Research Excellence on Achieving the Tobacco Endgame, School of Public Health, The University of Queensland, Brisbane, QLD, Australia 4006: c.gartner@uq.edu.au

Received 11 October 2021 Accepted 12 January 2022

\section{Check for updates}

(C) Author(s) (or their employer(s)) 2022. No commercial re-use. See rights and permissions. Published by BMJ.

To cite: Puljević $\mathrm{C}$,

Morphett K, Hefler M, et al. Tob Control

2022:31:365-375

\section{ABSTRACT}

Objective Tobacco endgame policies aim to rapidly and permanently reduce smoking to minimal levels. We reviewed evidence syntheses for: (1) endgame policies, (2) evidence gaps, and (3) future research priorities.

Data sources Guided by JBI scoping review methodology, we searched five databases (PubMed, CINAHL, Scopus, Embase and Web of Science) for evidence syntheses published in English since 1990 on 12 policies, and Google for publications from key national and international organisations. Reference lists of included publications were hand searched.

Study selection Two reviewers independently screened titles and abstracts. Inclusion criteria were broad to capture policy impacts (including unintended), feasibility, public and stakeholder acceptability and other aspects of policy implementation.

Data extraction We report the results according to the Preferred Reporting Items for Systematic Reviews and Meta-Analyses extension for Scoping Reviews checklist.

Data synthesis Eight policies have progressed to evidence synthesis stage (49 publications): mandatory very low nicotine content (VLNC) standard $(n=26)$; product standards to substantially reduce consumer appeal or remove the most toxic products from the market $(n=1)$; moving consumers to reduced risk products $(n=8)$; tobacco-free generation $(n=4)$; ending sales $(n=2)$; sinking lid $(n=2)$; tax increases $(n=7)$; and restrictions on tobacco retailers $(n=10)$. Based on published evidence syntheses, the evidence base was most developed for a VLNC standard, with a wide range of evidence synthesised.

Conclusions VLNC cigarettes have attracted the most attention, in terms of synthesised evidence. Additional focus on policies that reduce the availability of tobacco is warranted given these measures are being implemented in some jurisdictions.

\section{INTRODUCTION}

Tobacco endgame policies aim to permanently and rapidly reduce smoking prevalence to minimal levels when fully implemented. ${ }^{1-5}$ Tobacco endgame targets are specific, measurable outcomes that would indicate an end to the tobacco epidemic in a defined geographic area (eg, a country). Examples include reducing smoking prevalence to less than $5 \%$, or less than $1 \% .{ }^{6}$ Countries with endgame goals include: New Zealand (NZ; $<5 \%$ daily smoking for all population groups by $\left.2025^{8}\right)$, the UK ('smoke-free' by $\left.2030^{9}\right)$, Scotland $(<5 \%$ by $\left.2034^{10}\right)$, Ireland $\left(<5 \%\right.$ by $\left.2025^{11}\right)$, USA $(5 \%$ by $\left.2030^{12}\right)$, Canada $\left(<5 \%\right.$ by $\left.2035^{13}\right)$, Australia $(<5 \%$ by $\left.2030^{14}\right)$, Sweden $\left(<5 \%\right.$ by $\left.2025^{15}\right)$, Finland $\left(<5 \%\right.$ by $2030^{16}$ and $2 \%$ by $\left.2040^{17}\right)$ and Bangladesh ('tobacco free' by $2040^{18}$ ). Hence, there is increasing interest in endgame policies to achieve these targets.

Evidence synthesis (second generation knowledge) refers to any method of identifying, selecting and combining results from multiple empirical studies (first generation knowledge) to draw conclusions beyond a single study findings, ${ }^{19}$ and can be one indicator of progression towards translation of research evidence into policy. ${ }^{20-23}$ For example, the process of aggregating knowledge from individual studies is the second step of the 'Knowledge Creation' funnel in the 'Knowledgeto-Action' framework which posits that as 'knowledge moves through the funnel, it becomes more distilled and refined and presumably more useful to stakeholders'. ${ }^{21}$ Similarly, Christopher Whitty, the chief medical officer for England and chief medical adviser to the UK government since 2019, has described the 'accurate synthesis of existing information' as 'the most important single offering by academics to the policy process'. ${ }^{23}$

A 2016 qualitative synthesis identified 16 endgame policies focused on the product, user, market/supply or larger institutional structures, and highlighted a lack of evidence on their practicality or legality. ${ }^{5}$ Given the extant tobacco endgame literature has increased in recent years, it is timely to re-examine the synthesised evidence across policies with the potential to achieve a tobacco endgame.

\section{METHODS}

We compiled an initial a priori list of policies that are generally considered to be able to permanently and rapidly reduce smoking to minimal levels, if fully implemented, based on the expert opinion of the authorship team. These were considered to be inherently endgame policies (eg, policies that would end tobacco retail sales or make tobacco products non-addictive). Additional policies that could be endgame policies but were less clearly so, such as conventional approaches, identified through the 
Table 1 Policies with potential to achieve a tobacco endgame

\begin{tabular}{|c|c|}
\hline Policy category & Policy \\
\hline Produ & $\begin{array}{l}\text { 1. Mandate very low nicotine content (VLNC) for smoked tobacco products to make them non-addictive or minimally addictive. } \\
\text { 2. Set product standards for nicotine products that make combustible tobacco products unappealing or removed from the market for exceeding toxicity } \\
\text { thresholds. } \\
\text { 3. Move consumers from combustible tobacco products to non-smoked reduced risk nicotine products (eg, e-cigarettes, heated tobacco products, } \\
\text { smokeless tobacco products). }\end{array}$ \\
\hline User focused & $\begin{array}{l}\text { 4. Require consumers to obtain a purchaser's licence or medical prescription to purchase tobacco. } \\
\text { 5. Restrict tobacco sales by year born (tobacco-free generation). }\end{array}$ \\
\hline $\begin{array}{l}\text { Market/supply } \\
\text { focused }\end{array}$ & $\begin{array}{l}\text { 6. End commercial retail sale of combustible tobacco (abolition). } \\
\text { 7. Set a regularly reducing quota on the volume of tobacco products manufactured or imported into a country ('sinking lid'). } \\
\text { 8. Actions that reduce the commercial viability of tobacco companies, such as a 'corporate death penalty', or criminal charges (eg, 'corporate } \\
\text { manslaughter'), requiring compensation for full impacts of tobacco use, or limiting profitability. } \\
\text { 9. Increases in tobacco tax that make tobacco products generally unaffordable. } \\
\text { 10. Restrictions on tobacco retailer density/location/type/licensing that substantially reduce tobacco availability. }\end{array}$ \\
\hline focused & $\begin{array}{l}\text { 11. Transfer management of tobacco supply to an agency with a mandate to phase out tobacco sales, for example, regulated market model, non-profit } \\
\text { agency. } \\
\text { 12. Performance-based regulation whereby tobacco companies are required to meet smoking prevalence targets or be fined; or manufacturers pay a levy } \\
\text { based on sales volume similar to 'polluter pays' schemes. }\end{array}$ \\
\hline
\end{tabular}

literature search or discussion among the authorship team, were added to the review if they were examined in the evidence synthesis as a tobacco endgame policy (eg, product standards for palatability or toxicity, retailing restrictions, action against the tobacco industry, moving consumers to reduced risk products or tobacco tax increases). Evidence syntheses for these topics that did not specifically include consideration of the policy as part of an endgame strategy were excluded. Similar policies were grouped using the same broad categories of the 2016 endgame synthesis $^{5}$ (table 1 ).

We followed the JBI methodology for scoping reviews ${ }^{24}$ modified to restrict the sources to evidence syntheses, and the Preferred Reporting Items for Systematic Reviews and MetaAnalyses extension for Scoping Reviews checklist (online supplemental table 1). ${ }^{25}$ The protocol was pre-registered in Open Science Framework. ${ }^{26}$

\section{Review questions}

We addressed the following questions:

1. Which endgame policies have had an evidence synthesis performed?

2. Which types of evidence syntheses have been completed for tobacco endgame policies?

3. Which study designs contributed to the synthesised evidence?

4. Which countries and populations were included?

5. Were equity impacts addressed?

6. What research questions were addressed, and what gaps remain?

7. Which policy actors (government and non-government organisations, charitable and industry representatives) were involved in authoring, funding or publishing the evidence syntheses?

\section{Inclusion/exclusion criteria}

We included peer-reviewed journal articles and key reports from national and international health authorities such as the WHO, including systematic reviews, meta-analyses, rapid reviews, scoping reviews, narrative reviews, qualitative syntheses, simulation modelling studies and expert consensus studies. Simulation modelling studies were included because these studies combine data from multiple sources to estimate the effect of interventions on a simulated population in order to draw conclusions about the intervention. Expert consensus studies were also included because these use experts to synthesise and draw conclusions from the available evidence. Commentaries or editorials that included a substantive narrative review of the research evidence were included; opinion pieces or proposals without evidence directly related to the endgame policies were excluded. We included syntheses describing any evidence relevant to policy implementation, including unintended consequences (eg, adverse health effects) or tobacco industry responses (ie, not just evidence on the effectiveness of the policy). Only English language publications were included (due to unavailability of translation resources) published from 1 January 1990 to the date of the search. Syntheses were not excluded based on funding source, but information about the funder was extracted and reported.

\section{Search strategy}

A pilot search in PubMed identified title and abstract keywords from relevant articles and index terms, from which a search strategy was developed and finalised by CP and CEG (see online supplemental table 2). We searched five databases (PubMed, CINAHL, Scopus, Embase and Web of Science) using the search terms, and conducted targeted online searches for relevant reports, between 22 and 25 March 2021. Finally, we hand searched the reference lists of included evidence syntheses for additional relevant records.

\section{Evidence selection}

Figure 1 details the publication search and retrieval process. Each title and abstract was independently screened twice against the inclusion criteria in Rayyan software ${ }^{26}$ by two of 14 reviewers. The full text of publications that were not excluded at this title and abstract screening stage was then screened by the team of two reviewers. Conflicts were resolved through discussion with the senior author (CEG), who also conducted a final check of all included publications to ensure they met the criteria of being an evidence synthesis.

\section{Data extraction}

Data extraction was independently completed using an online form by one of 14 reviewers. Review articles were categorised into the review types listed by Sutton et al. ${ }^{27}$ As a consistency check, three team members (CEG, CP and KM) independently 


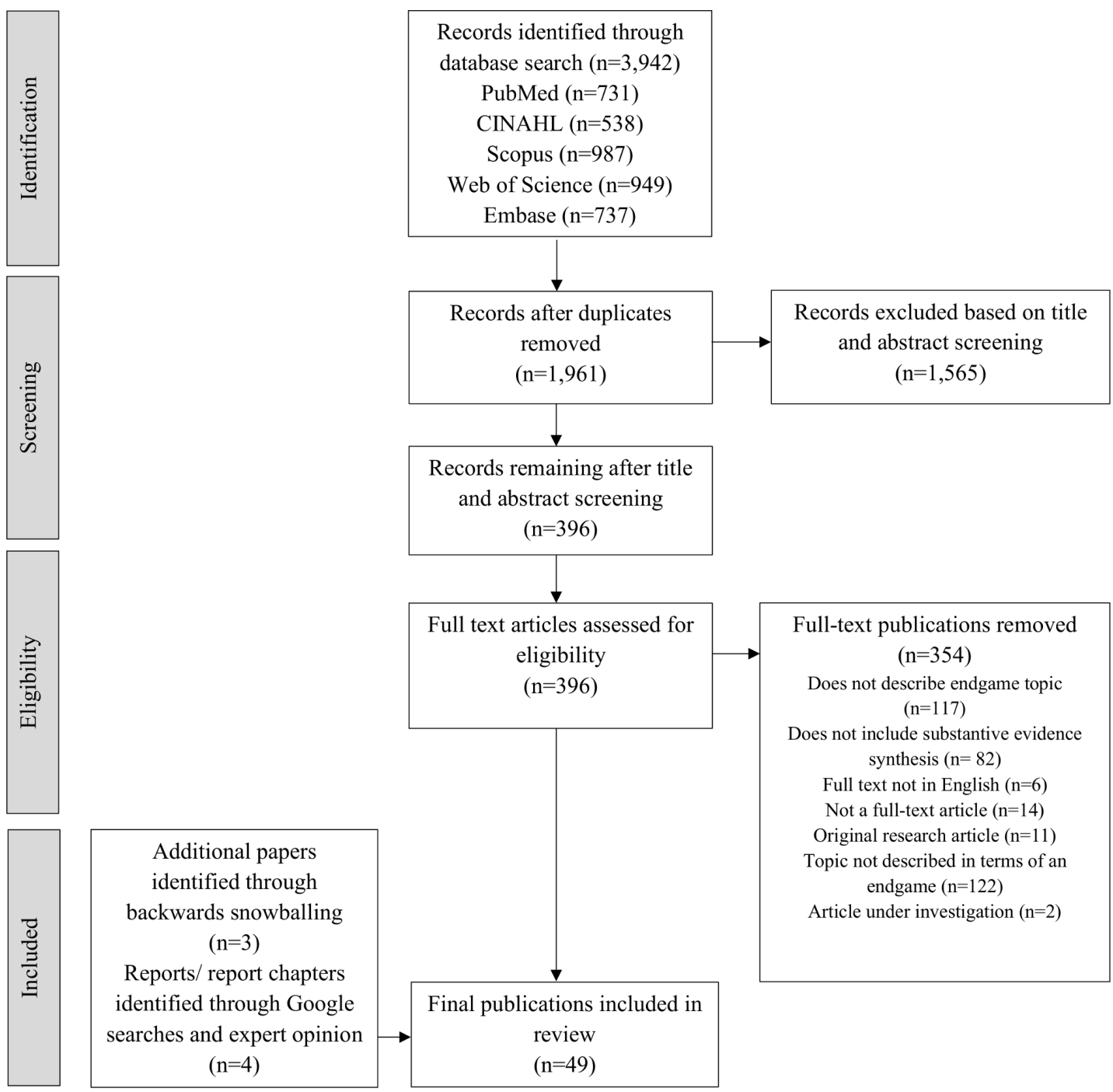

Figure 1 Preferred Reporting Items for Systematic Reviews and Meta-Analyses (PRISMA) flow diagram.

extracted data from the first three studies coded by each reviewer to ensure a consistent approach to data extraction. Any conflicts in data extraction approach were resolved through discussion with the senior author (CEG) and clarifying advice relayed to the reviewers performing the data extraction.

\section{RESULTS}

We included 49 publications, including 45 journal articles identified through database searches, 3 journal articles identified through backward snowballing and 4 reports or report chapters identified by internet searching (see figure 1) published by the WHO Study Group on Tobacco Product Regulation $(\mathrm{n}=2),{ }^{28} 29$ the National Academies of Science $(n=1)^{30}$ and the New Zealand Tobacco Control Research Tūranga $(n=1) .{ }^{31}$

Table 2 summarises the characteristics of the publications by endgame policy. Online supplemental table 3 summarises the research questions addressed and remaining evidence gaps noted by authors of the evidence syntheses, by endgame policy. Online supplemental tables 4-11 provide summaries of each evidence synthesis by endgame policy.

\section{Mandatory very low nicotine content standard}

Most syntheses that examined a very low nicotine content (VLNC) standard broadly summarised the existing evidence base and outlined evidence gaps, ${ }^{5} 28-3032-37$ rather than answering specific research questions. All evidence syntheses on this topic concluded that the policy is likely to result in a notable reduction in cigarette smoking. The modelling studies also concluded that mandating a VLNC standard for cigarettes would likely significantly reduce smoking prevalence and related harm. ${ }^{38-41}$ One traditional review reported the majority of smoking participants supported a VLNC standard in three surveys (in USA and NZ), while two surveys in the USA reported fewer than half supported the policy. ${ }^{5}$ Other topics explored by syntheses on this topic included policy implementation feasibility, ${ }^{42} 43$ the impact on use of other nicotine products or other drugs ${ }^{28}$ including alcohol ${ }^{44}$ and the potential impacts on people experiencing mental illness, ${ }^{28} 45-47$ socioeconomic disadvantage, ${ }^{47}$ pregnant women, ${ }^{28}$ women of childbearing age ${ }^{48}$ and Indigenous peoples, ${ }^{49}$ with authors of all these syntheses recommending a VLNC standard to achieve a tobacco endgame.

Potential limitations of the policy include some people reducing cigarettes smoked per day but not achieving cessation, or continuing to use cigarettes for a multitude of reasons other than nicotine addiction, ${ }^{35}$ public misperceptions that VLNC cigarettes are harmful ${ }^{50}$ and potential (short-term) negative impacts on behavioural and cognitive performance following a rapid reduction in nicotine. ${ }^{3651}$ 


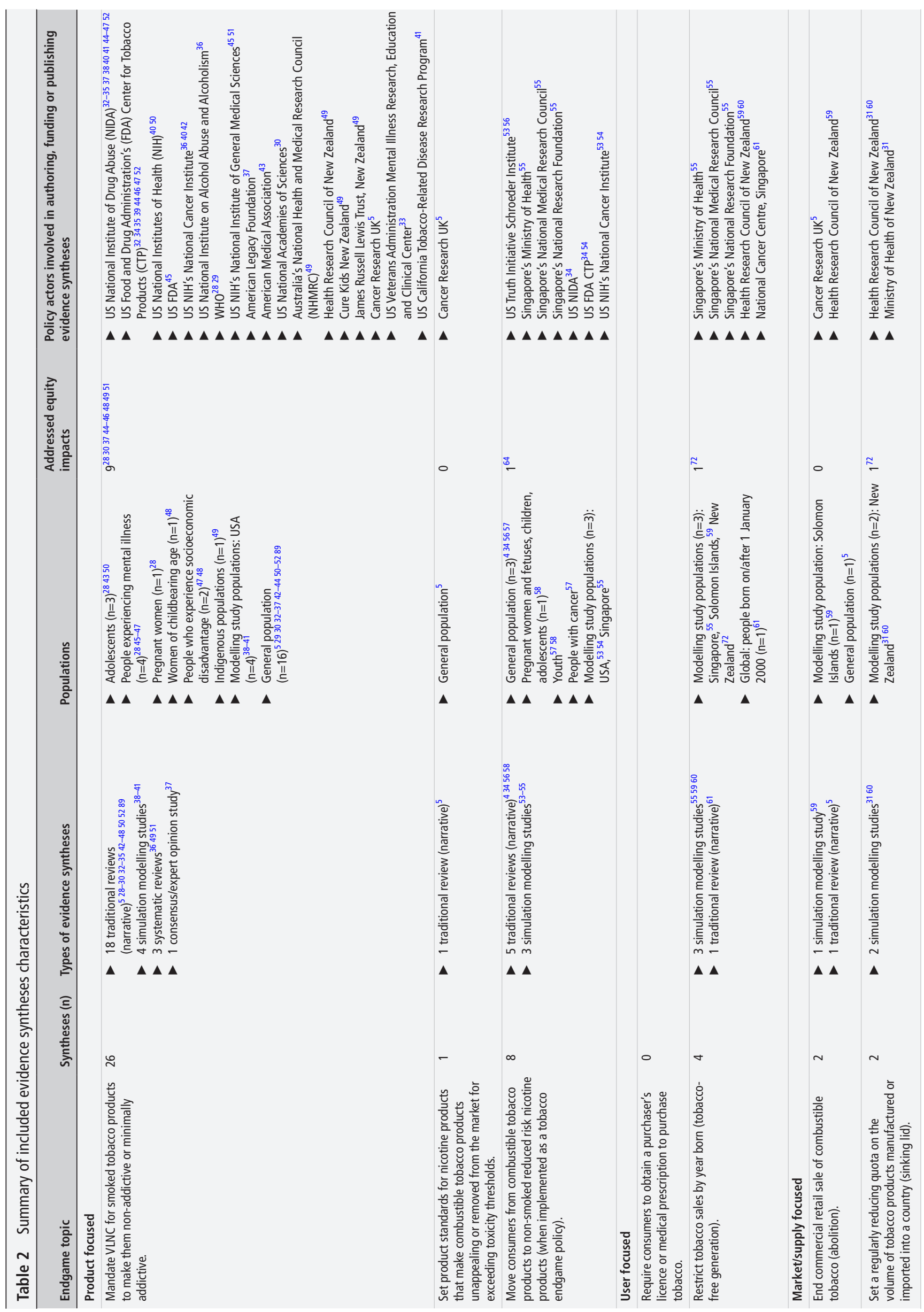




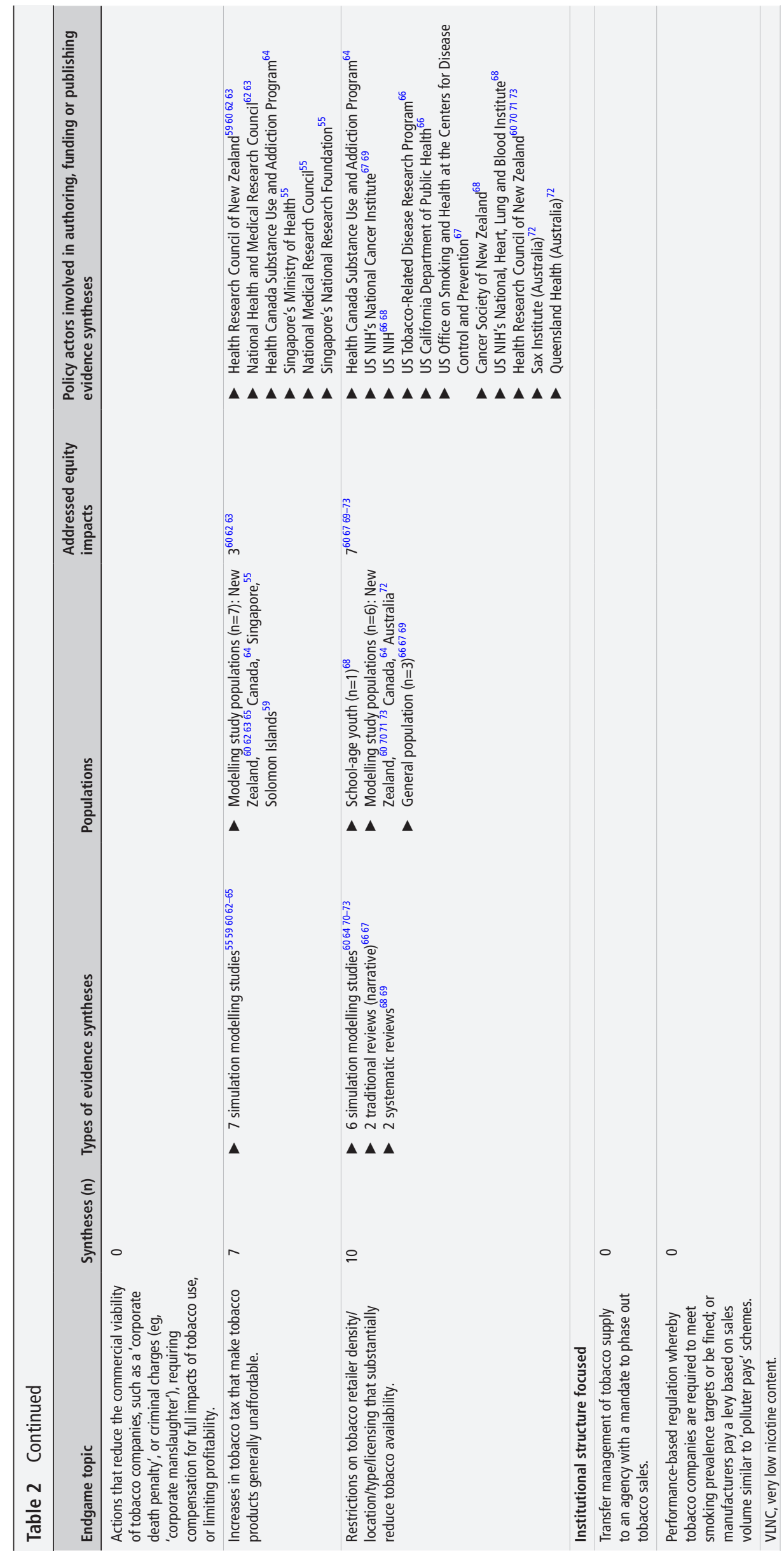


Most authors of evidence syntheses on this topic called for more research on the potential individual-level and populationlevel impacts of the policy, 529303739 including on mental and physical health outcomes, ${ }^{37} 384651$ and/or on priority populations. $2829323744-4649$ Several noted that the interaction of smoking VLNC cigarettes with alternative nicotine product use remains an evidence gap. ${ }^{353652}$ Some authors concluded that the remaining gaps in the evidence base should not prevent regulators from progressing policy making on a VLNC standard. ${ }^{36}$

\section{Set product standards that would reduce smoking or remove cigarettes from the market}

One narrative review covered product standards that would make combustible tobacco products substantially unappealing or that could lead to them being removed from the market due to the toxicity of their emissions. ${ }^{5}$ The review summarised various proposals to redesign cigarettes to make them unappealing, including raising their $\mathrm{pH}$ to 8 or more, making their smoke more acrid or banning all non-tobacco ingredients, menthol or filters. ${ }^{5}$ The authors also noted that banning certain constituents may result in the industry adding other potentially harmful ingredients as substitutes and identified the need for more research on the practicality and legality of this policy. The synthesis did not include evidence regarding the policy's potential effectiveness to achieve an endgame, only evidence of public support for banning menthol in cigarettes. Two public opinion polls offered conflicting results: one reported majority support for the policy and the other reported that the majority of participants held a neutral opinion.

\section{Reduced risk products}

Five syntheses, including three simulation modelling studies predicting the impacts of e-cigarette use, ${ }^{53-55}$ and two narrative reviews focusing on e-cigarettes, ${ }^{3456}$ concluded that these products have the potential to substantially reduce combustible tobacco use, and thus potentially achieve a tobacco endgame. ${ }^{34}$ 53-56 Three syntheses also summarised evidence on the harms of reduced risk products, all concluding that they are less harmful than combustible tobacco. ${ }^{56-58}$ One synthesis concluded that these products serve as promising harm reduction tools, ${ }^{56}$ with two noting that tobacco harm reduction should be complemented with other evidence-based interventions, ${ }^{4} 54$ such as phasing out cigarette sales. ${ }^{4}$ Some authors also noted the potential for reduced risk products to renormalise smoking, ${ }^{54}$ maintain smoking through dual use with tobacco cigarettes, ${ }^{56}$ and youth uptake of tobacco cigarettes. ${ }^{56}$

Authors called for more research on the impacts of reduced risk product use on health, ${ }^{345355}$ smoking cessation, ${ }^{54}$ subsequent tobacco smoking, particularly among youth, ${ }^{4}$ and effects of secondhand vapour. ${ }^{55}$ Evidence gaps related to the constituents and impacts of reduced risk products are likely to be topics that will require ongoing research and monitoring due to continuing changes in these products and the regulations governing them.

\section{Restrict tobacco sales by year born (tobacco-free generation)}

Evidence syntheses of the tobacco-free generation policy proposal included three simulation modelling studies and one traditional narrative review. The modelling studies ${ }^{555960}$ for Singapore, ${ }^{55}$ Solomon Islands ${ }^{59}$ and $\mathrm{NZ}^{60}$ concluded the policy has potential to achieve an endgame and substantial population-level health improvements. However, the NZ modelling study also indicated the policy alone would not be sufficient to achieve the NZ government's endgame goal of minimal smoking prevalence by $2025 .^{60}$ One traditional narrative review concluded that the proposal is ethical and legally defensible on human rights principles. ${ }^{61}$ The authors of one synthesis identified a need for more evidence on the policy's effectiveness. ${ }^{60}$

\section{End commercial retail tobacco sales}

A simulation modelling study found that the hypothetical eradication of cigarettes would achieve 1510 undiscounted healthadjusted life-years per 1000 people alive in the Solomon Islands in 2016. ${ }^{59}$ A narrative review outlined a variety of potential implementation models, presented arguments for and against the policy and summarised the results of surveys of public support for ending tobacco sales. ${ }^{5}$ Opponents suggest that like 1920s alcohol prohibition in the USA, it would be unpopular and ineffective, or that it would adversely impact people with lower education and incomes. Arguments in favour include that nicotine is not a recreational drug (unlike alcohol), that smoking is largely to satisfy addiction rather than for pleasure and targeted cessation assistance could mitigate adverse impacts on priority populations. ${ }^{5}$ The narrative review noted that surveys in Canada, USA, Australia, NZ, England, Hong Kong and Bhutan have measured public support for ending tobacco sales, with support ranging from 12\% (Ontario, Canada and NZ adolescents) to $88 \%$ (Bhutan) among people who smoke and from 24\% (Ontario, Canada) to 68\% (Hong Kong) among people who do not smoke. ${ }^{5}$ In two adult population surveys and one adolescent survey in NZ, support for ending tobacco sales in 10 years' time ranged from $50 \%$ to $72 \% .^{5}$ Neither publication summarised empirical evidence on the effectiveness of the proposal in achieving a tobacco endgame. Evidence gaps noted by the authors of the modelling study included a lack of diseasecosting studies for low-income and middle-income countries or a disease cost database to provide disease-specific healthcare expenditures for each country. ${ }^{59}$

\section{Sinking lid}

Two simulation modelling studies from NZ examined the sinking lid policy. ${ }^{3160}$ The first modelling study simulated the impact of tobacco companies bidding for tobacco supply quotas to the NZ market, ${ }^{31}$ and concluded that in a country with no domestic cigarette manufacturing, the policy is equivalent to an import quota restriction that sets a maximum limit on the amount of tobacco that can be imported. The second estimated that the policy would result in a gain of 282000 quality-adjusted life-years, proequity impacts (3.3 times more health gain per capita for NZ Māori than non-Māori people) and cost savings of \$NZ5430 million. ${ }^{60}$

\section{Increases in tobacco tax}

Seven simulation modelling studies examined the potential impacts of tobacco tax increases within the context of an endgame strategy. The four modelling studies that estimated health outcomes all concluded that tax increases would result in notable population health improvements, ${ }^{55596062}$ and the four that reported changes in smoked tobacco use all estimated significant decreases in prevalence, ${ }^{55606364}$ thus demonstrating the policy could contribute to an endgame. However, the only synthesis (a modelling study) that demonstrated how a tobacco endgame could be achieved solely through raising taxes showed they would need to increase by more than 20\% (above inflation) annually, ${ }^{64}$ a figure notably higher than Australia's $12.5 \%$ annual tax increases between 2017 and 2020. One synthesis concluded the policy would result in sizeable decreases in health 
inequalities between Māori and non-Māori people in NZ, ${ }^{62}$ and two noted decreased health system costs. ${ }^{6062}$ One estimated that the policy would result in substantial increases in tax revenue, ${ }^{63}$ while another projected minimal impact on taxation revenue. ${ }^{64}$ Another study modelled the impacts of lower taxes for VLNC cigarettes, thereby examining the use of tax measures as part of implementing another endgame policy. ${ }^{65}$ The authors concluded this policy would reduce nicotine exposure and smoking-related healthcare costs. ${ }^{65}$ Potential limitations of the policy discussed in the syntheses included loss of government revenue, ${ }^{64}$ or exacerbation of financial hardship among socioeconomically disadvantaged smokers. ${ }^{63}$ Authors of other syntheses called for more evidence on the policy's cost-effectiveness, ${ }^{65}$ effectiveness in reducing smoking prevalence ${ }^{60}$ and impact in conjunction with other policies (eg, mass media campaigns). ${ }^{62}$

\section{Retailer restrictions}

Two traditional narrative reviews provided broad evidence overviews of restricting tobacco retailer density, location, type or licensing ${ }^{6667}$ concluding that these are likely effective strategies for reducing population-level tobacco use, ${ }^{66}$ and would be most effective when complementing multiple WHO Framework Convention on Tobacco Control approaches. ${ }^{67}$ Two systematic reviews examined the association between adolescent smoking and density or proximity of retailers to schools and homes, ${ }^{68} 69$ finding adolescent smoking was positively correlated with retailer density and proximity. Six simulation modelling studies concluded that restricting tobacco retailer density or location would reduce smoking prevalence ${ }^{606470-72}$ and health system costs, ${ }^{607173}$ and increase health gains ${ }^{607173}$ and tobacco prices. ${ }^{70}$ One modelling study concluded that restricting tobacco sales to only $50 \%$ of liquor stores would result in a greater decrease in smoking prevalence than a $95 \%$ reduction in the number of tobacco retail outlets, ${ }^{70}$ while another concluded that restricting tobacco sales to pharmacies only (combined with cessation advice) would substantially decrease smoking prevalence and increase population health. ${ }^{71}$ Potential policy limitations include opposition from the retail sector, ${ }^{69}$ and smokers ${ }^{6869}$ and perpetuating health inequalities in socioeconomically disadvantaged communities. ${ }^{69}$ Authors called for more research on the policy's effectiveness in reducing tobacco use, ${ }^{69-72}$ causal associations between rates of tobacco use, changes in the density or proximity of retailers, ${ }^{687273}$ cost-effectiveness, ${ }^{69}$ burden on individuals, ${ }^{69}$ intended and unintended consequences ${ }^{66}$ and impacts in rural areas. ${ }^{68}$

\section{Equity impacts of endgame strategies}

Eighteen (37\%) publications included at least one mention of the equity impact of the policy. Very few syntheses substantively addressed equity impacts (eg, ref 45-47 49); the remainder that did mention equity impacts only briefly acknowledged potential equity impacts that were reported in one or two empirical studies in their review (eg, ref 28 44). Identified equity considerations related to the impact of endgame policies on people who experience low income, ${ }^{53}$ low education, ${ }^{53}$ mental illness ${ }^{28} 45-47$ and socioeconomic disadvantage, ${ }^{47}$ or identify as Indigenous. ${ }^{49} 72$ Several simulation modelling studies from NZ investigated the potential impact of various endgame policies on Māori versus non-Māori populations. ${ }^{6062637173}$ Only one study focused on the impact of endgame policies on low-income country populations. ${ }^{59}$

Most of these syntheses concluded that endgame policies are likely to result in greater health benefits for priority populations compared with the general population, with these policies including a VLNC standard, ${ }^{46-48}$ reduced risk products, ${ }^{53}$ tobacco-free generation, ${ }^{60}$ a sinking lid, ${ }^{60}$ tax increases ${ }^{62}$ and retail restrictions. ${ }^{73}$ Conversely, two syntheses noted that the impact of endgame policies is unlikely to differ among these populations compared with the general population, ${ }^{48} 49$ and four modelling studies (reported in three publications) concluded that tax increases, ${ }^{60} 63$ restricting tobacco sales to only pharmacies, ${ }^{71}$ or reducing the number of tobacco retailers, ${ }^{60}$ are likely to result in greater reductions in smoking prevalence among nonMāori people compared with Māori people. Other syntheses highlighted a need to be aware of increased risk of adverse outcomes associated with endgame policies among these populations, ${ }^{69}$ including increased risk of withdrawal symptoms ${ }^{44}$ or mood impacts ${ }^{45}$ when quitting smoking. Some syntheses simply highlighted a need for higher prioritisation of tobacco control measures among these populations, ${ }^{30} 4649$ while others mentioned that the equity impacts of endgame policies are a worthy future research focus (eg, ref 28).

\section{DISCUSSION}

We identified 49 evidence syntheses describing eight tobacco endgame policies. About half (53\%) of these related to the product-focused policy of mandating a VLNC standard for cigarettes. The majority of syntheses on this topic were traditional narrative reviews or simulation modelling studies, and covered a broad range of questions relevant to policy implementation such as effectiveness in facilitating smoking cessation, health impacts and potential unintended consequences. While a VLNC standard is yet to be implemented in any country, the NZ government has announced that all smoked tobacco products sold in NZ must comply with a VLNC standard by $2025 .^{\circ}$ The US FDA also issued an advance notice of proposed rulemaking for a tobacco product standard for nicotine level of combusted cigarettes in March 2018. ${ }^{74}$ Our scoping review shows that there is a substantial supportive evidence base available to guide policy makers regarding the implementation of a VLNC standard. The other product-focused policy for which we found multiple evidence syntheses was moving consumers to reduced risk products as part of an endgame strategy. Most of these evidence syntheses supported these products' potential role in achieving endgame goals, although with uncertainty concerning potential unintended impacts, such as long-term health effects. 34535557 Measures supporting a move from smoked tobacco to reduced risk products have been mentioned in some countries' tobacco endgame policy documents (eg, England, ${ }^{75}$ Canada $^{13}$ and $\mathrm{NZ}^{8}$ ), suggesting that this endgame policy has been implemented in some form.

Only two of the eight evidence syntheses describing reduced risk products examined substitute nicotine products other than e-cigarettes (smokeless tobacco ${ }^{4}$ and heated tobacco products ${ }^{34}$ ), reflecting the much greater focus on e-cigarettes since their development. However, despite the rapid expansion of e-cigarettes in some markets, particularly the UK, USA and NZ, the rate of decline in smoking in these countries has not been at a rate that would achieve an endgame, ${ }^{76-78}$ suggesting additional policies to encourage smoking cessation are needed. Interestingly, the two countries that have proposed implementing a VLNC standard for cigarettes-the USA and NZ-have both linked this policy to the availability of reduced risk nicotine products to satisfy the consumer demand for nicotine and to reduce demand for illicit tobacco products, which could increase if a mandatory VLNC standard was implemented. ${ }^{879}$ Hence, encouraging consumers 
to move to reduced risk products may have most potential to contribute to an endgame as a complementary intervention to other policies that focus on combustible tobacco products.

In addition to a VLNC standard, the Aotearoa New Zealand Action Plan also proposes restricting cigarette design features that increase consumer appeal, and consideration of how to restrict filters to decrease the impact of discarded cigarette filters on the environment. It did not specify a ban on filtered cigarettes. ${ }^{8}$ We identified only one evidence synthesis related to product standards targeting consumer appeal, ${ }^{5}$ showing the greater research focus on reducing the addictiveness of cigarettes as a policy target rather than reducing attractiveness. No evidence was reported in the synthesis on the feasibility, acceptability or potential impacts of banning filters, ${ }^{5}$ indicating a substantial gap, and making it difficult to draw conclusions on the potential for this policy to contribute to achieving an endgame goal.

We identified relatively fewer evidence syntheses related to user-focused, market/supply-focused and institutional structurefocused policies, apart from increasing tobacco taxes, which may be politically difficult to raise to the level required to achieve endgame targets. However, given there are an increasing number of examples of successful and unsuccessful attempts to implement supply restrictions, the research evidence in this area is likely to be increasing. Some of these supply-focused policies should be prioritised for future empirical research and evidence syntheses, particularly those that have reached an advanced stage in the policy-making process. For example, there have been both successful and unsuccessful attempts to introduce a tobacco-free generation policy in various subnational jurisdictions, including the introduction of an unsuccessful bill in the state of Tasmania (Australia) ${ }^{80}$ implementation in Balanga City Council (Philippines) ${ }^{81}$ and Brookline City Council (USA). ${ }^{82}$ Furthermore, NZ is set to become the first country to introduce a national law to ban supplying smoked tobacco products to anyone born after a certain date. ${ }^{8}$ The evidence syntheses we reviewed provided support for the ethicality and legality of this proposed law based on human rights principles, ${ }^{61}$ and the modelling studies demonstrated substantial health benefits to the population. ${ }^{55560}$ Consistent with the findings of the NZ simulation modelling, which demonstrated that this policy would be insufficient to achieve the country's endgame goal, ${ }^{60}$ the proposed law will be introduced as part of a comprehensive plan that also addresses adults who currently smoke. ${ }^{8}$

Ending commercial tobacco sales has also been implemented in Bhutan (although recently reversed) ${ }^{83}$ and two local government areas in the USA (Beverly Hills and Manhattan Beach). ${ }^{84}$ In Hungary, legislation introduced in 2013 forced a reduction in the number of tobacco retailers from more than 40000 to 7000 retail outlets, ${ }^{85}$ and reducing the number of tobacco retailers or the availability of tobacco are government policy goals in NZ and Australia. ${ }^{8}{ }^{14}$ Hence, there are increasing opportunities to conduct research evaluating the intended and unintended consequences of these supply-focused endgame policies as they are being implemented. Such research would help inform policy making in jurisdictions yet to implement these policies. While we identified only two evidence syntheses on ending commercial tobacco sales, ${ }^{59}$ we identified 10 that considered a policy of restricting tobacco retailing as part of an endgame strategy. ${ }^{60} 6466-73$ These evidence syntheses suggested that reducing tobacco retailer density could reduce both adolescent and adult smoking rates, although the studies cited were generally cross-sectional studies of smoking behaviour and retailer density. Hence, as noted by multiple authors of these syntheses, longitudinal studies are an important evidence gap to fill with research from jurisdictions that have rapidly reduced the number of tobacco retailers. The modelling studies that estimated the potential impact of reducing tobacco retailer density indicated that very substantial reductions will be needed in combination with additional policies to reach endgame goals.

We did not identify any evidence syntheses for the policies of: (1) requiring a medical prescription or licence to purchase tobacco; (2) transferring management of tobacco supply to an agency, such as a government or non-profit entity; (3) performance-based regulation, whereby tobacco companies are required to meet smoking prevalence targets or be penalised; or (4) action that would reduce the commercial viability of tobacco companies, such as governments imposing a corporate death penalty, implementing price caps (or maximum wholesale price) for cigarettes that would limit the tobacco manufacturers' profitability to levels that would be commercially unacceptable or taking legal action that could make cigarette companies commercially unviable, such as charging executives with corporate manslaughter for tobacco-related deaths. A traditional narrative review discussed these policies, but did not synthesise any empirical studies related to them. ${ }^{5}$

\section{General recommendations for future research directions}

This scoping review provides a broad overview of the evidence syntheses related to tobacco endgame policies. The results can help researchers and policy makers identify relevant existing literature reviews, consensus studies and simulation modelling studies for tobacco endgame policies, and prioritise empirical research and evidence syntheses for currently under-represented policies.

We recommend more focus on equity impacts; only $37 \%$ of evidence syntheses mentioned equity, despite multiple authors calling for more research on the impact of endgame policies among priority populations in recognition of the disproportionate health, financial and social impacts of smoking on these populations. ${ }^{86} 87$ Similarly, with only one evidence synthesis focused on low-income countries, ${ }^{59}$ there is a need for more research on the feasibility and effectiveness of tobacco endgame policies in these regions, especially considering that these countries are experiencing an increasing proportion of the global burden of tobacco-related disease. ${ }^{88}$ While the focus in lowincome countries has been on implementing strategies that have a strong evidence base, implementing endgame policies at an earlier stage in the tobacco epidemic (at increasing or peak prevalence stages), as is the case in these countries, might avoid the enormous death toll that will occur if these countries follow the same slow incremental approach to introducing tobacco control policies that was followed in high-income countries. However, there is little research on the feasibility of implementing endgame strategies at an earlier stage of the tobacco epidemic.

As approximately half $(\mathrm{n}=25 ; 51 \%)$ of included syntheses were traditional narrative reviews, and 24 (49\%) did not contain a methods section, we recommend that future evidence syntheses on tobacco endgame policies employ more rigorous, detailed and systematic approaches to synthesising relevant evidence. Because empirical evidence on the effectiveness of most endgame policies is currently unavailable due to a lack of implementation, additional robust studies are needed to improve estimation of effect sizes, such as examining examples of implementation (or partial implementation) or using experimental approaches to measure consumer preferences. Other under-researched areas include public and policy-maker preferences regarding which endgame policies to prioritise, features of policy implementation (eg, 
timelines) and how these differ by country context, legal aspects of implementation and potential unintended impacts, such as the impact on the illicit tobacco market.

\section{Strengths and limitations}

A strength of this scoping review was the comprehensive literature search that covered a wide range of potential tobacco endgame policies, providing an overview of the state of evidence synthesis in this field. Nevertheless, we may have missed some relevant publications or policies. There is no consensus on which tobacco control policies are endgame policies. Arguably, many conventional policies could be endgame policies if implemented with sufficient intensity, such as taxation. We relied on expert judgement as to which policies should be included in the search strategy. As a scoping review, we did not conduct a quality assessment of the literature. However, we did note that many of the publications did not provide details of their methods for selecting and synthesising the evidence. Because we only examined evidence syntheses rather than empirical studies, our findings likely do not reflect all available evidence on these policies. Finally, we reported the evidence gaps as they were reported by the authors of the evidence syntheses. Hence, these reflect their perspectives. Some evidence gaps may have been subsequently addressed in more recent empirical research, or in evidence syntheses that were outside the scope of our review. For example, many of the noted evidence gaps concerning reduced risk products, retailing restrictions, product standards for palatability or toxicity, industry litigation or other industry regulation, and tobacco taxation may be addressed in other evidence syntheses that were not included in our review, as we only included syntheses on these topics that considered these interventions specifically as endgame policy interventions.

\section{CONCLUSION}

The majority of evidence syntheses of tobacco endgame policies reviewed product-focused policies (mandating a VLNC standard, moving consumers to reduced risk products, and other product standards to reduce palatability or toxicity), with fewer syntheses published on policies that target how tobacco products are supplied (user-focused, supply-focused or institutional structure-focused policies). Further research and evidence syntheses on potential endgame polices are needed, particularly prioritising those policies that are already being implemented

\section{What this paper adds}

$\Rightarrow$ Tobacco endgame policies aim to permanently and rapidly reduce tobacco smoking prevalence to minimal levels.

$\Rightarrow$ Following a 2016 qualitative synthesis describing 16 tobacco endgame policies, it is timely to re-examine the synthesised evidence on policies with the potential to achieve a tobacco endgame.

$\Rightarrow$ We identified 49 evidence syntheses describing eight tobacco endgame policies.

$\Rightarrow$ The endgame strategies that have received the most attention in terms of synthesised evidence were mandatory very low nicotine content (VLNC) cigarettes and moving consumers to reduced risk products.

$\Rightarrow$ Future evidence syntheses should employ rigorous and systematic approaches, and focus on policies already being implemented (eg, retailer restrictions, commercial tobacco retail sales bans and restricting sales by birth year). such as tobacco retailer reductions, commercial tobacco retail sales bans and restricting sales by birth year. A greater focus on equity impacts is also needed. Finally, future evidence syntheses should employ rigorous and systematic approaches.

\section{Author affiliations}

${ }^{1}$ NHMRC Centre of Research Excellence on Achieving the Tobacco Endgame, School of Public Health, The University of Queensland, Brisbane, Queensland, Australia ${ }^{2}$ School of Public Health, The University of Queensland, Brisbane, Queensland, Australia

${ }^{3}$ Centre for Health Services Research, The University of Queensland, Brisbane, Queensland, Australia

${ }^{4}$ Menzies School of Health Research, Charles Darwin University, Casuarina, Northern Territory, Australia

${ }^{5}$ Department of Public Health, University of Otago, Wellington, New Zealand

${ }^{6}$ Centre for Addiction Research, Faculty of Medicine and Health Sciences, The University of Auckland, Auckland, New Zealand

${ }^{7}$ National Institute for Health Innovation, University of Auckland, Auckland, New Zealand

${ }^{8}$ Research School of Population Health, Australian National University, Canberra, Australian Capital Territory, Australia

${ }^{9}$ School of Psychological Sciences, The University of Melbourne, Melbourne, Victoria, Australia

${ }^{10}$ Melbourne School of Population and Global Health, University of Melbourne, Melbourne, Victoria, Australia

${ }^{11}$ College of Public Health, Medical and Veterinary Sciences, James Cook University, Cairns, Queensland, Australia

${ }^{12}$ College for Medicine and Public Health, Flinders University, Adelaide, South Australia, Australia

Twitter Cheneal Puljević @ChenealPuljevic, Kylie Morphett @kyliemorphett, Marita Hefler@m_hef and Coral E Gartner @CoralGartner

Acknowledgements Thank you to Mr Scott McIntyre for providing research librarian advice and support. We would also like to thank Professor Patricia McDaniel and two anonymous reviewers who provided detailed and helpful comments on the manuscript.

Contributors Conceptualisation: CEG. Refinement of study design and protocol: all authors. Title, abstract and full-text screening and data extraction: CP, KM, CEG, MLG, AP, DAO, DS, MAK, NW, GC, DPT, MH, KC, RE. First draft of manuscript: CP. Revision of manuscript: $C E G, C P, K M, R B, B B, T B, R E, M H$, JH, DS, AP, NW, MAK, CB, KC.

Funding This study is funded by an NHMRC grant (GNT1198301). AP receives an Australian Research Development Training Program stipend.

Competing interests None declared.

Patient consent for publication Not required.

Ethics approval This study does not involve human participants.

Provenance and peer review Commissioned; externally peer reviewed.

Supplemental material This content has been supplied by the author(s). It has not been vetted by BMJ Publishing Group Limited (BMJ) and may not have been peer-reviewed. Any opinions or recommendations discussed are solely those of the author(s) and are not endorsed by BMJ. BMJ disclaims all liability and responsibility arising from any reliance placed on the content. Where the content includes any translated material, BMJ does not warrant the accuracy and reliability of the translations (including but not limited to local regulations, clinical guidelines, terminology, drug names and drug dosages), and is not responsible for any error and/or omissions arising from translation and adaptation or otherwise.

\section{ORCID iDs}

Kylie Morphett http://orcid.org/0000-0003-4322-8825

Marita Hefler http://orcid.org/0000-0002-1709-1098

Richard Edwards http://orcid.org/0000-0003-2264-9823

David P Thomas http://orcid.org/0000-0002-8653-0621

Janet Hoek http://orcid.org/0000-0003-4362-1539

Billie Bonevski http://orcid.org/0000-0001-8505-622X

Coral E Gartner http://orcid.org/0000-0002-6651-8035

\section{REFERENCES}

1 Malone RE. The race to a tobacco endgame. Tob Control 2016;25:607-8.

2 Malone RE. Imagining things otherwise: new endgame ideas for tobacco control. Tob Control 2010;19:349-50.

3 Thomson $\mathrm{G}$, Edwards R, Wilson $\mathrm{N}$, et al. What are the elements of the tobacco endgame? Tob Control 2012;21:293-5. 
4 van der Eijk Y. Development of an integrated tobacco endgame strategy. Tob Control 2015;24:336-40.

5 McDaniel PA, Smith EA, Malone RE. The tobacco endgame: a qualitative review and synthesis. Tob Control 2016;25:594-604.

6 Houghton F, Houghton S, O'Doherty D, et al. The tobacco endgame: the importance of targets and geography. Can J Public Health 2018;109:900-1.

7 Smith EA, Malone RE. An argument for phasing out sales of cigarettes. Tob Control 2020:29:703-8.

8 Ministry of Health. Smokefree Aotearoa 2025 action plan. Wellington: New Zealand Government, 2021. https://www.health.govt.nz/system/files/documents/publications/ hp7801___smoke_free_action_plan_v15_web.pdf

9 Cabinet Office and Department of Health and Social Care. Advancing our health: prevention in the 2020s. United Kingdom: United Kingdom Government, 2019.

10 Scottish Government. Tobacco Control Strategy - Creating a Tobacco-Free Generation. Scotland: Scottish Government, 2013.

11 Healthy Ireland, Department of Health. Tobacco free Ireland. Ireland: Department of Health, 2019.

12 Office of Disease Prevention and Health Promotion. Reduce current cigarette smoking in adults — TU-02. Health people 2030. Rockville, MD: U.S. Department of Health and Human Services, 2021.

13 Government of Canada. Canada's Tobacco Strategy. Canada: Government of Canada, 2020. https://www.canada.ca/en/health-canada/services/publications/healthy-living/ canada-tobacco-strategy.html

14 Department of Health. National preventive health strategy. Canberra: Australian Government, 2021-2030. https://www.health.gov.au/resources/publications/nationalpreventive-health-strategy-2021-2030

15 Library of Congress. Sweden: new rules on smoking in public places and sale of tobacco enter into force. Available: https://www.loc.gov/item/global-legal-monitor/ 2019-09-25/sweden-new-rules-on-smoking-in-public-places-and-sale-of-tobaccoenter-into-force/ [Accessed 2 Dec 2021].

16 World Health Organization Regional Office for Europe. Strong legislation helps defeat e-cigarettes in Finland. Geneva, Switzerland: World Health Organization, 2020. https://www.euro.who.int/en/countries/finland/news/news/2020/5/strong-legislationhelps-defeat-e-cigarettes-in-finland

17 Ministry of Social Affairs and Health. Roadmap to a tobacco-free Finland: action plan on tobacco control. Finland: Ministry of Social Affairs and Health, 2014. https:// julkaisut.valtioneuvosto.fi/bitstream/handle/10024/70305/URN_ISBN 978-952-003513-6.pdf

18 Government of the People's Republic of Bangladesh. Sustainable development goals: Bangladesh progress report 2020. Dhaka, Bangladesh: Bangladesh Planning Commission, 2020. https://www.bd.undp.org/content/bangladesh/en/home/library/ democratic_governance/bangladesh-sustainable-development-goals--sdgs--progressreport-.html

19 Cornell University Library. A guide to evidence synthesis: types of evidence synthesis. Ithaca, NY: Cornell University Library, 2021.

20 Alper BS, Haynes RB. EBHC pyramid 5.0 for accessing preappraised evidence and guidance. Evid Based Med 2016;21:123-5.

21 Graham ID, Logan J, Harrison MB, et al. Lost in knowledge translation: time for a map? J Contin Educ Health Prof 2006;26:13-24.

22 Greenhalgh T, Thorne S, Malterud K. Time to challenge the spurious hierarchy of systematic over narrative reviews? Eur I Clin Invest 2018:48:e12931.

23 Whitty CJM. What makes an academic paper useful for health policy? BMC Med 2015;13:301.

24 Peters M, Godfrey C, Mclnerney P. Chapter 11: Scoping reviews (2020 version). In: Aromataris E, Munn Z, eds. JBI manual for evidence synthesis. JBI, 2020.

25 Tricco AC, Lillie E, Zarin W, et al. PRISMA extension for scoping reviews (PRISMA-ScR): checklist and explanation. Ann Intern Med 2018:169:467-73.

26 Puljevic C. Closing the gaps in tobacco endgame evidence: a scoping review and gap analysis. Open Science Framework 2021.

27 Sutton A, Clowes M, Preston L, et al. Meeting the review family: exploring review types and associated information retrieval requirements. Health Info Libr 2019:36:202-22.

28 Ferris Wayne G, Donny E, Ribisl KM. A global nicotine reduction strategy: state of the science. In: Report on the scientific basis of tobacco product regulation: seventh report of a WHO Study Group. Geneva: World Health Organization, 2019. https://apps.who. int/iris/handle/10665/161512

29 WHO Study Group on Tobacco Product Regulation. Advisory note: Global nicotine reduction strategy. In: Report on the scientific basis of tobacco product regulation: fifth report of a WHO Study Group. Geneva: World Health Organization, 2015. https:// apps.who.int/iris/rest/bitstreams/848180/retrieve

30 Institute of Medicine. Ending the tobacco problem: a blueprint for the nation. Washington, DC: The National Academies Press, 2007.

31 Tait P, Saunders C, Rutherford P. Quota management policy for new Zealand tobacco supply. Auckland: New Zealand Tobacco Control Research Tūranga, University of Auckland, 2013

32 Donny EC, Hatsukami DK, Benowitz NL, et al. Reduced nicotine product standards for combustible tobacco: building an empirical basis for effective regulation. Prev Med 2014;68:17-22
33 Sofuoglu M, LeSage MG. The reinforcement threshold for nicotine as a target for tobacco control. Drug Alcohol Depend 2012:125:1-7.

34 Smith TT, Hatsukami DK, Benowitz NL, et al. Whether to push or pull? Nicotine reduction and non-combusted alternatives - two strategies for reducing smoking and improving public health. Prev Med 2018;117:8-14.

35 White CM, Hatsukami DK, Donny EC. Reducing the relative value of cigarettes: considerations for nicotine and non-nicotine factors. Neuropharmacology 2020;175:108200

36 Berman ML, Glasser AM. Nicotine reduction in cigarettes: literature review and gap analysis. Nicotine Tob Res 2019;21:\$133-44.

37 Hatsukami DK, Perkins KA, Lesage MG, et al. Nicotine reduction revisited: science and future directions. Tob Control 2010;19:e1-10.

38 Ahmad S, Billimek J. Estimating the health impacts of tobacco harm reduction policies: a simulation modeling approach. Risk Anal 2005;25:801-12.

39 Apelberg BJ, Feirman SP, Salazar E, et al. Potential public health effects of reducing nicotine levels in cigarettes in the United States. N Eng/ J Med 2018;378:1725-33.

40 Levy DT, Cummings KM, Heckman BW, et al. The public health gains had cigarette companies chosen to sell very low nicotine cigarettes. Nicotine Tob Res 2021;23:438-46.

41 Tengs TO, Ahmad S, Savage JM, et al. The AMA proposal to mandate nicotine reduction in cigarettes: a simulation of the population health impacts. Prev Med 2005:40:170-80.

42 Benowitz NL, Henningfield JE. Reducing the nicotine content to make cigarettes less addictive. Tob Control 2013;22(Suppl 1):i14-17.

43 Henningfield JE, Benowitz NL, Slade J, et al. Reducing the addictiveness of cigarettes. Council on scientific Affairs, American Medical association. Tob Control 1998;7:281-93.

44 Dermody SS, Donny EC. The predicted impact of reducing the nicotine content in cigarettes on alcohol use. Nicotine Tob Res 2014;16:1033-44.

45 Gaalema DE, Miller ME, Tidey JW. Predicted impact of nicotine reduction on smokers with affective disorders. Tob Regul Sci 2015;1:154-65.

46 Tidey JW, Davis DR, Miller ME, et al. Modeling nicotine regulation: a review of studies in smokers with mental health conditions. Prev Med 2018;117:30-7.

47 Tidey JW, Muscat JE, Foulds J, et al. Reducing the nicotine content of cigarettes: effects in smokers with mental health conditions and socioeconomic disadvantages. Nicotine Tob Res 2019;21:S26-8

48 Kurti AN. Reducing tobacco use among women of childbearing age: contributions of tobacco regulatory science and tobacco control. Exp Clin Psychopharmacol 2020:28:501-16.

49 Johnston V, Westphal DW, Glover M, et al. Reducing smoking among Indigenous populations: new evidence from a review of trials. Nicotine Tob Res 2013:15:1329-38

50 Villanti AC, Byron MJ, Mercincavage M, et al. Misperceptions of nicotine and nicotine reduction: the importance of public education to maximize the benefits of a nicotine reduction standard. Nicotine Tob Res 2019;21:S88-90.

51 Keith DR, Kurti AN, Davis DR, et al. A review of the effects of very low nicotine content cigarettes on behavioral and cognitive performance. Prev Med 2017;104:100-16

52 White CM, Pickworth WB, Sved AF, et al. Using product standards to render the most harmful tobacco products minimally addictive: maximum nicotine level, non-nicotine constituents, and scope. Nicotine Tob Res 2019:21:S13-15.

53 Levy DT, Borland R, Lindblom EN, et al. Potential deaths averted in USA by replacing cigarettes with e-cigarettes. Tob Control 2018;27:18-25.

54 Mendez D, Warner KE. A magic bullet? The potential impact of e-cigarettes on the toll of cigarette smoking. Nicotine Tob Res 2021;23:654-61.

55 Doan TTT, Tan KW, Dickens BSL, et al. Evaluating smoking control policies in the ecigarette era: a modelling study. Tob Control 2020;29:522-30.

56 Abrams DB, Glasser AM, Villanti AC, et al. Managing nicotine without smoke to save lives now: evidence for harm minimization. Prev Med 2018;117:88-97.

57 Brandon TH, Goniewicz ML, Hanna NH, et al. Electronic nicotine delivery systems: a policy statement from the American association for cancer research and the American Society of clinical oncology. J Clin Oncol 2015:33:952-63.

58 England LJ, Bunnell RE, Pechacek TF, et al. Nicotine and the developing human: a neglected element in the electronic cigarette debate. Am J Prev Med 2015;49:286-93.

59 Singh A, Petrović-van der Deen FS, Carvalho N, et al. Impact of tax and tobacco-free generation on health-adjusted life years in the Solomon Islands: a multistate life table simulation. Tob Control 2020;29:388-97.

60 van der Deen FS, Wilson N, Cleghorn CL, et al. Impact of five tobacco endgame strategies on future smoking prevalence, population health and health system costs: two modelling studies to inform the tobacco endgame. Tob Control 2018:27:278-86

61 van der Eijk Y, Porter G. Human rights and ethical considerations for a tobacco-free generation. Tob Control 2015;24:238-42.

62 Blakely T, Cobiac LJ, Cleghorn CL, et al. Health, health inequality, and cost impacts of annual increases in tobacco tax: multistate life table modeling in New Zealand. PLOS Med 2015;12:e1001856.

63 Cobiac $\mathrm{L}$, Ikeda T, Nghiem N, et al. Modelling the implications of regular increases in tobacco taxation in the tobacco endgame. Tob Control 2015;24:e154-60. 
64 Chaiton M, Dubray J, Guindon GE, et al. Tobacco endgame simulation modelling: assessing the impact of policy changes on smoking prevalence in 2035. Forecasting 2021;3:267-75.

65 Laugesen M. Modelling a two-tier tobacco excise tax policy to reduce smoking by focusing on the addictive component (nicotine) more than the tobacco weight. $N Z$ Med J 2012;125:35-48.

66 Henriksen L. The retail environment for tobacco: a barometer of progress towards the endgame. Tob Control 2015;24:e1-2.

67 Kong AY, King BA. Boosting the tobacco control vaccine: recognizing the role of the retail environment in addressing tobacco use and disparities. Tob Control 2021;30:e162-8.

68 Marsh L, Vaneckova P, Robertson L, et al. Association between density and proximity of tobacco retail outlets with smoking: a systematic review of youth studies. Health Place 2021;67:102275

69 Glasser AM, Roberts ME. Retailer density reduction approaches to tobacco control: a review. Health Place 2021;67:102342.

70 Pearson AL, van der Deen FS, Wilson N, et al. Theoretical impacts of a range of major tobacco retail outlet reduction interventions: modelling results in a country with a smoke-free nation goal. Tob Control 2015;24:e32-8.

71 Petrović-van der Deen FS, Blakely T, Kvizhinadze G, et al. Restricting tobacco sales to only pharmacies combined with cessation advice: a modelling study of the future smoking prevalence, health and cost impacts. Tob Control 2019;28:643-50.

72 Skinner A, Walker P, Atkinson J-A, et al. Policy options for endgame planning in tobacco control: a simulation modelling study. Tob Control 2021;30:77-83.

73 Pearson AL, Cleghorn CL, van der Deen FS, et al. Tobacco retail outlet restrictions: health and cost impacts from multistate life-table modelling in a national population. Tob Control 2017;26:579-85.

74 Food and Drug Administration. Tobacco product standard for nicotine level of combusted cigarettes: a proposed rule. Fed Reg 2018;83:11818-43 https://www. federalregister.gov/documents/2018/03/16/2018-05345/tobacco-product-standardfor-nicotine-level-of-combusted-cigarettes

75 Department of Health. Towards a Smokefree generation: a tobacco control plan for England. London: UK Government, 2017. https://www.gov.uk/government/ publications/towards-a-smoke-free-generation-tobacco-control-plan-for-england
76 Levy DT, Tam J, Sanchez-Romero LM, et al. Public health implications of vaping in the USA: the smoking and vaping simulation model. Popul Health Metr 2021;19:19.

77 Cancer Intelligence Team Cancer Research UK. Smoking prevalence projections for England, Scotland, Wales, and Northern Ireland, based on data to 2018/19. London: Cancer Research UK, 2020. https://www.cancerresearchuk.org/sites/default/files/ cancer_research_uk_smoking_prevalence_projections_february_2020_final.pdf

78 Ministry of Health. Proposals for a Smokefree Aotearoa 2025 action plan. Auckland: New Zealand Government, 2021. https://www.health.govt.nz/publication/proposalssmokefree-aotearoa-2025-action-plan

79 Gottlieb S, Zeller M. A Nicotine-Focused framework for public health. N Eng/ J Med 2017;377:1111-4.

80 Walters EH, Barnsley K. Tobacco-free generation legislation. Med J Aust 2015:202:509-10.

81 de Leon K, Sarita JT. The Philippines: pioneering the tobacco endgame. Tob Control 2020.

82 Cromar A. Tobacco-Free generation: Brookline passes new restriction aiming to phase out tobacco sales to young smokers. Bostoncom. Boston, MA, 2020

83 Givel MS. History of Bhutan's prohibition of cigarettes: implications for neoprohibitionists and their critics. Int J Drug Policy 2011;22:306-10.

84 McDaniel PA, Malone RE. Tobacco industry and public health responses to state and local efforts to end tobacco sales from 1969-2020. PLoS One 2020;15:e0233417.

85 World Health Organization. Hungary - new regulation of tobacco sales introduced. WHO framework convention on tobacco control 2013.

86 Bonevski B, Borland R, Paul CL, et al. No smoker left behind: it's time to tackle tobacco in Australian priority populations. Med J Aust 2017;207:141-2.

87 Clegg LX, Reichman ME, Miller BA, et al. Impact of socioeconomic status on cancer incidence and stage at diagnosis: selected findings from the surveillance, epidemiology, and end results: national longitudinal mortality study. Cancer Causes Control 2009;20:417-35.

88 Hoe C, Kennedy RD, Spires M, et al. Improving the implementation of tobacco control policies in low-and middle-income countries: a proposed framework. BMJ Glob Health 2019;4:e002078.

89 Walker N, Bullen C, McRobbie H. Reduced-nicotine content cigarettes: is there potential to aid smoking cessation? Nicotine Tob Res 2009;11:1274-9. 